\title{
ERRATUM
}

\section{Erratum to: RE: Doing What Comes Naturally}

\author{
Mark C. Henderson', Gurpreet Dhaliwal', Stephen R. Jones ${ }^{3}$, Charles Culbertson', and Judith L. \\ Bowen $^{7}$
}

'Department of Internal Medicine, UC Davis Medical Center, Sacramento, CA, USA; ${ }^{2}$ Department of Medicine, University of California, San Francisco and the San Francisco Veterans Affairs Medical Center, San Francisco, CA, USA; ${ }^{3}$ Department of Internal Medicine, Legacy Health System and Oregon Health and Sciences University, Portland, OR, USA.

J Gen Intern Med 25(10):1138

DOI: $10.1007 / \mathrm{s} 11606-010-1339-4$

(c) Society of General Internal Medicine 2010

$\mathrm{T}$ he abdominal CT image (Fig. 2) in the original article marked the adrenal mass incorrectly. The following image has an arrow demonstrating the correct location of the adrenal mass. The authors and editors regret this error.

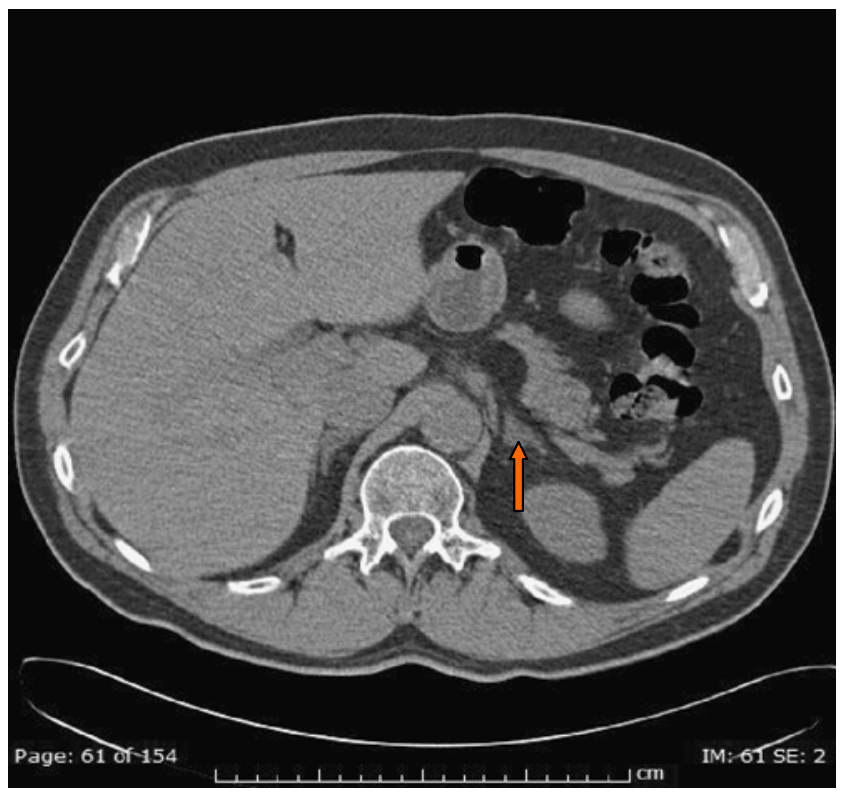

The online version of the original article can be found under doi:10.1007/s11606-009-1187-2.

Corresponding Author: Mark C. Henderson, Department of Internal Medicine, UC Davis Medical Center, Sacramento, CA, USA (e-mail: MCHenderson@ucdavis.edu)

Published online April 20, 2010 